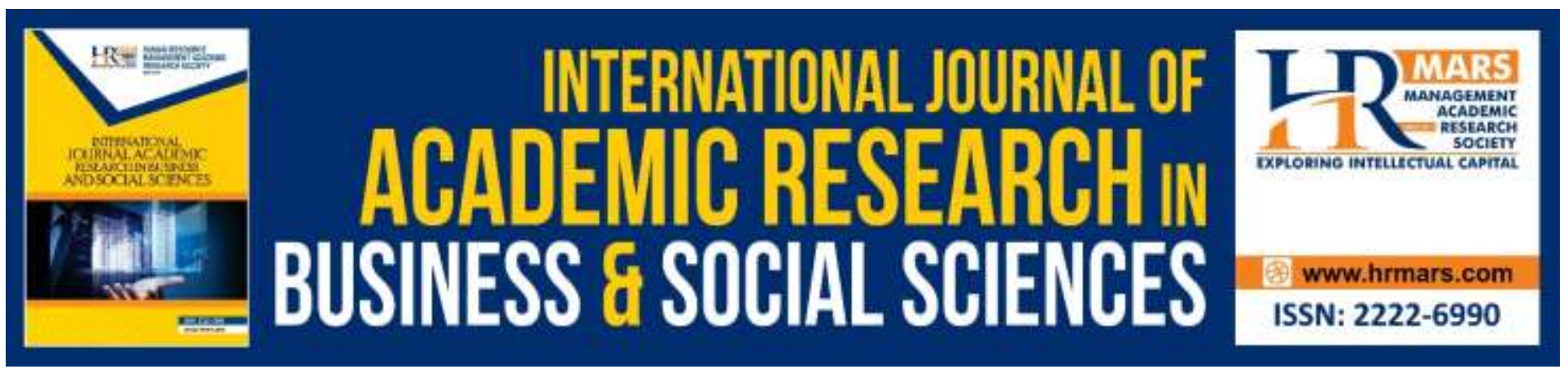

\title{
Exploring the Social Exclusion of People Living With HIV/Aids in Kano State, Nigeria
}

Auwalu Sale Yakasai, Norizan Abdul Ghani

To Link this Article: http://dx.doi.org/10.6007/IJARBSS/v10-i4/7140

DOI:10.6007/IJARBSS/v10-i4/7140

Received: 23 February 2020, Revised: 01 March 2020, Accepted: 26 March 2020

Published Online: 10 April 2020

In-Text Citation: (Yakasai \& Ghani, 2020)

To Cite this Article: Yakasai, A. S., \& Ghani, N. A. (2020). Exploring the Social Exclusion of People Living With HIV/Aids in Kano State, Nigeria. International Journal of Academic Research in Business and Social Sciences, 10(4), 371-379.

Copyright: (c) 2020 The Author(s)

Published by Human Resource Management Academic Research Society (www.hrmars.com)

This article is published under the Creative Commons Attribution (CC BY 4.0) license. Anyone may reproduce, distribute, translate and create derivative works of this article (for both commercial and non-commercial purposes), subject to full attribution to the original publication and authors. The full terms of this license may be seen

at: http://creativecommons.org/licences/by/4.0/legalcode

\section{Vol. 10, No. 4, 2020, Pg. 371 - 379}

Full Terms \& Conditions of access and use can be found at http://hrmars.com/index.php/pages/detail/publication-ethics 


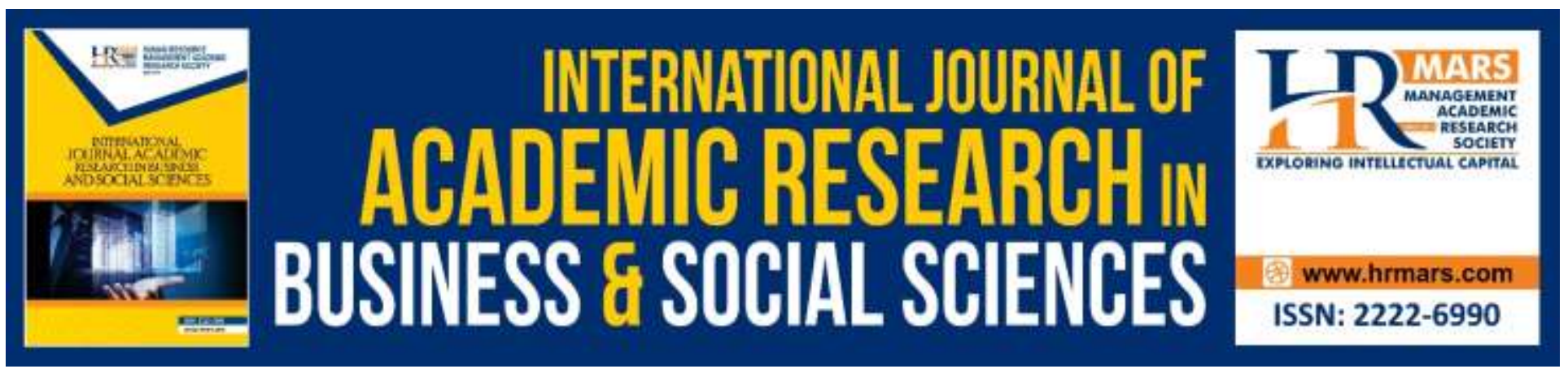

\title{
Exploring the Social Exclusion of People Living With HIV/Aids in Kano State, Nigeria
}

\author{
Auwalu Sale Yakasai, Norizan Abdul Ghani \\ Faculty of Applied Social Sciences, Universiti Sultan Zainal Abidin, Terengganu, Malaysia \\ Email: si3249@putra.unisza.edu.my,norizabd@unisza.edu.my
}

\begin{abstract}
This paper aims to examine the social exclusion of people living with HIV/AIDS (PLWHA) in Kano State, Nigeria. Social exclusion from family members, friends, co-workers, groups, and institutions commences the moment someone is diagnosed HIV positive. This is attributed to a misconception of how the virus is spread from the victims to other people. To explore the social exclusion of people living with HIV/AIDS in Kano State, Nigeria, with a view to make recommendations on how to minimize it among people living with HIV/AIDS in the State. Social exclusion can be significantly reduced if the recommendations are accepted and implemented by the stakeholders. The role of the stakeholders cannot be overstated in this aspect. Government at all levels, health personnel, traditional leaders, religious leaders, local and international organisations, support groups, institutions, family members should play a very significant role in decreasing the incidence of social exclusion among the people living with HIV/AIDS in the state.
\end{abstract}

Keywords: Community, Exploring, Kano State, PLWHA, Social Exclusion

\section{Introduction}

The first formal case of Acquired Immunodeficiency Syndrome in Nigeria (AIDS) was reported in 1986. Nigeria has almost 3.8 million people living with HIV, the second-largest universally. Stigma and discrimination are key barriers to testing, treatment uptake, and adherence (Odimegwu, Akinyemi, \& Alabi, 2017). But in 2012, the HIV prevalence in the overall population, as testified by National AIDS and Reproductive Health Survey (NARHS), had decreased to some extent, from $3.6 \%$ in 2007 to $3.4 \%$ (Childrenandaids, 2017).

Nigeria is the second leading HIV epidemic in the world (National Agency for the Control of AIDS (NACA), 2017). Though HIV prevalence amongst adults is much less (2.8\%) than in other sub-Saharan African nations such as South Africa (18.8\%) and Zambia (11.5\%). In 2017, 3.1 million persons had HIV in Nigeria (UNAIDS 'AIDSinfo,' 2018). 
INTERNATIONAL JOURNAL OF ACADEMIC RESEARCH IN BUSINESS AND SOCIAL SCIENCES Vol. 10, No. 4, April, 2020, E-ISSN: 2222-6990 @ 2020 HRMARS

UNAIDS projected that around two-thirds of new HIV infections in West and Central Africa in 2017 took place in Nigeria. Together with South Africa and Uganda, the country accommodates around half of all new HIV infections in sub-Saharan Africa annually (UNAIDS, 2017)._This is despite accomplishing a 5\% reduction in new infections between 2010 and 2017 (UNAIDS, 2018).

Undefended heterosexual sex is responsible for $80 \%$ of new HIV infections in Nigeria, with the majority of remaining HIV infections happening in key affected populations such as sex workers (NACA, 2015).

Figure 1.1

\section{NIGERIA New HIV infections by age and sex (2017)}

Children and adults
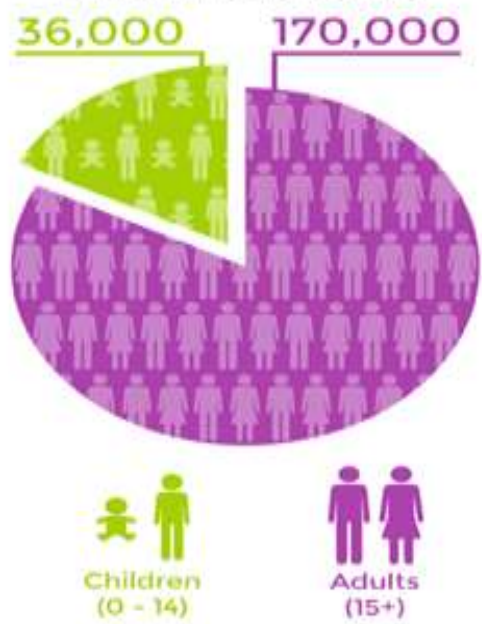

Adolescents
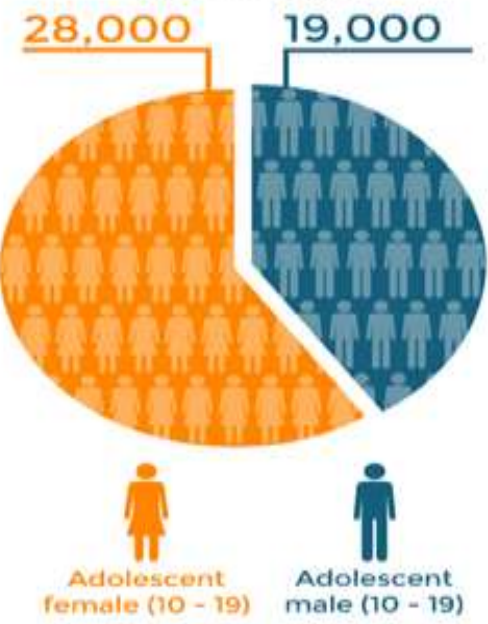

Young people
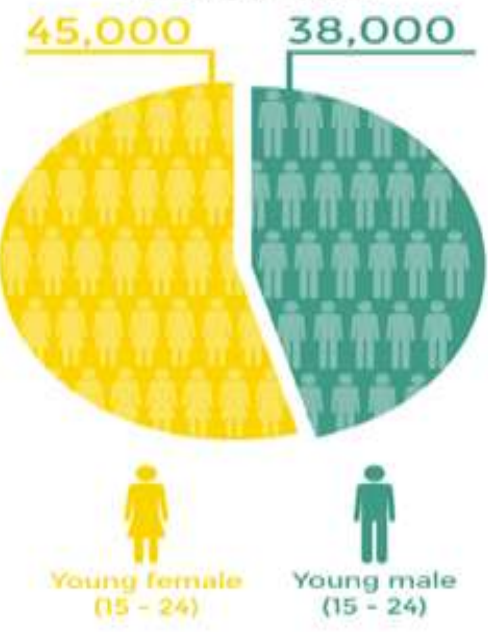

Avert) www.avertorg

Social exclusion is a complex and multi-dimensional process. It involves the lack or denial of resources, rights, goods and services, and the inability to participate in the normal relationships and activities, available to the majority of people in a society, whether in economic, social, cultural or political arenas. It affects both the quality of life of individuals and the equity and cohesion of society as a whole (Levitas et al., 2018).

\section{Stigma}

HIV-associated stigma refers to "negative beliefs, feelings and attitudes towards people living with HIV, their families, people who work with them (HIV service providers), and members of groups that have been heavily impacted by HIV, such as gay and bisexual men, homeless people, street youth, and mentally ill people." (CDC \& Division of HIV/AIDS Prevention, 2018).

\section{Discrimination}

"HIV discrimination refers to the unfair and unjust treatment of someone based on their real or perceived HIV status." Discrimination may also upset family and friends, and those who are involved 
INTERNATIONAL JOURNAL OF ACADEMIC RESEARCH IN BUSINESS AND SOCIAL SCIENCES Vol. 10, No. 4, April, 2020, E-ISSN: 2222-6990 @ 2020 HRMARS

in the care for people with HIV. Human Immunodeficiency Virus discrimination is frequently fired by myths of casual transmission of HIV and pre-existing prejudices against certain groups, certain sexual behaviours, drug usage, and fear of disease and death. Discrimination can be established by-laws, policies, and practices (CDC \& Division of HIV/AIDS Prevention, 2018).

Stigma has socio-economic effects on people living with HIV/AIDS in Kano, which includes rejection from family, friends, neighbours, coworkers, etc. and unemployment as well as customers' rejection of goods and services they sell and provide respectively. This paper aims to examine the social exclusion of people living with HIV/AIDS (PLWHA) in Kano State. According to empirical research conducted, $25 \%$ of ART patients stated that they had faced stigma related or discrimination related challenges at family, hospital, and community levels and their working place. Kinds of stigma experienced comprised accusing for becoming HIVpositive and calling with distinct names such as (prostitute, skeleton, unfaithful individual, and the remainder). For instance, discriminatory behaviours against PLHIV in hospital (selective use of gloves, poor quality care, and separation from other patients); community (social isolation, restriction in family events, and hostility); family (not sharing of cutleries and toilet facilities, breach of confidentiality); as well as workplace (threat of employment termination, isolation by coworkers) are common (Odimegwu et al., 2017).

Even though mere social relations like eating, sitting, talking, walking, working, or bathing together or through hugging and kissing, do not transmit HIV It is observed with dismay that people living with HIV/AIDS suffer from various forms of social stigma which culminate into social, physical, economic as well as political discrimination that can lead to joblessness, loneliness, depression, shyness, and psychological problems. This can further deteriorate their health condition.

Based on the various studies conducted, there is a significant relationship between HIV-related stigma and higher rates of depression, lesser social support, and lower levels of compliance to antiretroviral medications and accessibility to and utilization of health and social services. Again, Poor relationships were observed between HIV-related stigma and anxiety, life quality, physical health as well as emotional and mental distress, and sexual risk practices. Whereas the threat of bias assessments revealed overall good quality pertinent to how HIV stigma and health outcomes were assessed on the included studies, a high risk of bias among specific studies was noticed in the relation of appropriate control for potential confounders. Additional research should focus on expounding the justification behind the negative relationship between stigma and health to enlighten interventions better to shrink the impact of stigma on the health and well-being of people living with HIV (Rueda et al., 2016).

According to Rueda et al. (2016), HIV related stigma in this context has been defined as disregarding, discrediting, and discriminating against people alleged to have HIV. Stigma continues to be rampant in the context of HIV, both in terms of the attitudes of people that are not infected or concerning the experiences of those living with HIV. The manner through which those living with HIV may experience stigma comprises enacted stigma, anticipated stigma, and internalised stigma. Enacted stigma is the kind of discrimination experienced by people with HIV in real life, and can include acts of violence and marginalisation. Anticipated stigma is alertness of undesirable social views towards HIV and the 
expectation that a person living with HIV will come across stigma and discrimination in the future. Internalised stigma means the commendation of negative beliefs, opinions, and feelings of oneself as it relates to one's HIV positive status. Stigma can arise from misunderstandings about how HIV can pass from one person to another individual from judgmental attitudes towards those social groups that are excessively affected by HIV, including men who have sex with men (MSM). Chambers, Rueda, and Baker (2015) assert that a recent review of the qualitative evidence indicated that HIV related stigma is a wide-ranging and universal social phenomenon that reveals within multiple social domains, such as healthcare environments.

Reports from Studies on HIV discrimination in healthcare facilities portrayed rejection of care or treatment, HIV testing deprived of consent, contravening of confidentiality, negative attitudes, and embarrassing practices among healthcare personnel. Models linking the experience to negative results were developed and tested, particularly in terms of racial discrimination, physical and mental health, and substance use. HIV related stigma is related to lesser mental health outcomes, such as emotional distress, shame, depression, reduced self-esteem, reduced psychological functioning, minor psychological adjustment, negative affect, anxiety, suicidal ideation, life satisfaction, quality of life, and stress associated with disclosure. Other studies have acknowledged the effect of stigma on a person's self- valuation or mental outlook once his or her status is identified. Stigma has also been interrelated with secondary health-related factors comprising seeking healthcare and compliance with antiretroviral treatment (Rueda et al., 2016).

Namadi (2019), in his research conducted on awareness, knowledge, and attitudes towards HIV/AIDS among long-distance truck drivers in Kano State, Nigeria, reveals that the respondents have a negative attitude towards people with HIV/AIDS.

In research carried out on Domestic Violence among Women Living with HIV/AIDS in Kano, Northern Nigeria, the results reveal that $17.5 \%$ to $27.4 \%$ experienced domestic violence resulting in HIV diagnosis. Precisely, 30.0\% had physical violence (including slapping, kicking, and punching), 59.3\% had verbal violence (insults and threats), and $10.7 \%$ suffered emotional violence (Iliyasu, Abubakar, Babashani, \& Galadanci, 2011).

\section{The National Agency for the Control Of Aids (NACA)}

The National Agency for the Control of AIDS (earlier National Action Committee on AIDS) was set up in February 2000 to manage the diverse activities of HIV/AIDS in Nigeria.

\section{Mission}

To provide an enabling policy environment and stable ongoing facilitation of proactive multi-sectoral planning coordinated implementation, monitoring, and evaluation of all HIV/AIDS prevention and impact mitigation activities in Nigeria. 


\section{Vision}

To make Nigeria, a nation of people with a functional knowledge of HIV/AIDS who provide care and support to individuals, families, and communities confronted with the epidemic and the agency solely authorized to facilitate all stakeholder HIV/AIDS activities in the country.

Amongst other purposes, NACA's mandates are to:

1. Coordinate and sustain advocacy by all sectors and at all levels for HIV/AIDS/STDs Expanded Responses in Nigeria;

2. Develop the framework for collaboration and support from all stakeholders for a multisectoral and multi-disciplinary response to HIV/AIDS in Nigeria;

3. Develop and present to the Presidential Council on AIDS, PCA, all plans on HIV/AIDS in Nigeria for policy decisions;

4. Develop and articulate a strategic plan for an Expanded National Response to HIV/AIDS in Nigeria;

5. Coordinate, monitor and evaluate the implementation of the Strategic National Plan for the control of HIV/AIDS/STDs in Nigeria and all other approved policies;

6. Coordinate and facilitate the mobilization of resources for an effective and sustainable response to HIV/AIDS/STDs in Nigeria, and

7. Undertake any other duties as assigned by the PCA from time to time.

Nigeria is the most populous nation in Africa, having about 170 million people. It has reported presently an HIV prevalence of 3.4\%, which is next to South Africa in Sub-Saharan Africa. The response of the Nigerian government to the epidemic is centered on a national strategic work plan known as the HIV/AIDS Emergency Action Plan, which formerly was a four-year plan with a US \$190 million costs for programme implementation. The plan was intended to be jointly implemented by the Government of Nigeria, bilateral donors, and a World Bank IDA credit.

The HIV/AIDS Emergency Action Plan (HEAP) document recognized over 200 activities that the government is to accomplish over four years. Intended to promote a multi-sectoral, participatory response to HIV/AIDS prevention and impact mitigation, the HEAP directed the implementation of activities and appropriate allocation of available resources.

In 2004-2005 at the termination of the life of the HEAP, a current framework, the National Strategic Framework (NSF) was established with extensive participation from Civil Society, the Private sector, Government entities, and executing bodies and the international donor community in Nigeria. The NSF planned with a life span of 5 years would guide the National Response, and all implementing and coordinating entities to contain the disseminating epidemic.

The National Agency for the Control of AIDS helps to ensure that entities and groups responsible for the implementation of the NSF objectives and activities get the financial, organizational and human resources support necessary to assume and complete assigned tasks in a multi-sectoral environment; NACA also serves to make sure that all associates in the war against HIV/AIDS. 
INTERNATIONAL JOURNAL OF ACADEMIC RESEARCH IN BUSINESS AND SOCIAL SCIENCES Vol. 10, No. 4, April, 2020, E-ISSN: 2222-6990 @ 2020 HRMARS

\section{NACA Mandate}

1. Plan and coordinate activities of the various sectors in the National Response Strategic Framework;

2. Facilitate the engagement of all tiers of government and all areas on issues of HIV/AIDS prevention, care, and support;

3. Advocate for the mainstreaming of HIV/AIDS interventions into all sectors of the society;

4. Formulate policies and guidelines on HIV/AIDS;

5. Support HIV/AIDS research in the country;

6. Mobilize resources (local and foreign) and equitable coordinate application for HIV/AIDS activities;

7. Provide and coordinate linkages with the global community on HIV/AIDS;

8. Monitor and evaluate all HIV/AIDS activities in the country;

9. Facilitate the development and management of the policies and strategies of all sectors to ensure the human, financial, and organizational resources to support the successful execution of the national HIV/AIDS response programme.

10. Establish, encourage and promote training programme for the employees of the Agency and other appropriate persons from public or private organizations;

11. Perform such functions as may, from time to time be assigned to it by the Government; and 12.Facilitate collaboration for the management of HIV and opportunistic infections (NACA,2019).

\section{Conclusion}

he paper has highlighted the extent of social exclusion that exists among people living HIV/AIDS, which is regarded as daunting. This is attributed to the misconception of the means of the spread of HIV. But efforts are being made for the social inclusion of people living with HIV/AIDS in all the socioeconomic activities of their respective societies. This is done through massive enlightenment by the government and all the stakeholders such as international and local non-governmental organisations working with PLWHA, traditional and religious leaders, the association of PLWHA, support groups for PLWHA, health professionals, etc.

\section{Recommendations}

1. The government should enact laws and policies to protect people living with HIV/AIDS.

2. Both international and local non-governmental organisations working with people living with HIV/AIDS should embark on massive enlightenment to the general public that HIV is not transmitted through mere social interaction like sitting or eating together with PLWHA, shaking hands with them, etc.

3. Family members should give total support to any member diagnosed HIV positive by coming close and interact freely with the victim.

4. Traditional leaders play a very vital role in moulding the behaviour of their members. Therefore, they need to make sure those with HIV are not excluded in all daily affairs.

5. Religious leaders steer the activities of their members. They should disseminate information during Jumma'a sermon, religious lessons that Islam emphasizes the importance and reward of caring for the sick persons, and that social interaction is not a means of contracting HIV. 
INTERNATIONAL JOURNAL OF ACADEMIC RESEARCH IN BUSINESS AND SOCIAL SCIENCES Vol. 10, No. 4, April, 2020, E-ISSN: 2222-6990 @ 2020 HRMARS

6. Mass media is one of the key agents of socialization. It plays a very significant role in shaping behaviour. It should dispel the rumour that HIV is transmitted by mere close contact with the victims.

7. People living with HIV/AIDS should form a morestrong association to fight for their rights, educate the community on the only ways HIV is transmitted. This will trim down the degree of stigma and social exclusion.

8. More powerful support groups for PLWHA need to be created to support the victims and strengthen their good relationship with the general members of society.

9. Health workers, by their qualifications and experience, should serve as a role model by coming close to victims. They also provide intensive and extensive health education to the community to dispel the rumours that HIV can be transmitted via body contact, such as handshaking.

10. The general public should not blame anybody due to his/her disease condition. They should understand that anyone can fall sick at any time. So they should accept them and not run away from them.

\section{References}

CDC \& Division of HIV/AIDS Prevention. (2018). Stigma and Discrimination / Living With HIV / HIV Basics / HIV/AIDS / CDC. Retrieved from https://www.cdc.gov/hiv/basics/livingwithhiv/stigmadiscrimination.html

Chambers, L., Rueda, S., Baker, D. (2015). Stigma, HIV, and health: a qualitative synthesis. BMC Public Health

Childrenandaids. (2017) Federal Republic of Nigeria National Hiv And Aids Strategic Framework 20172021 National Strategic

Fahmy, E., Sutton, E., \& Pemberton, S. (2018). Understanding social exclusion: The views of the UK public. Journal of Poverty and Social Justice, 26(3), 439-458. https://doi.org/10.1332/175982718X15361436360832

Iliyasu, Z., Abubakar, I. S., Babashani, M., \& Galadanci, H. S. (2011). Domestic Violence among Women Living with HIV / AIDS in Kano, African Journal of Reproductive Health, Vol. 15, pp. 41-50.

Khairuldin, W. M. K. F. B. W., Embong, A. H., Hassan, S. A., Yasin, M. F. M., \& Anas, W. N. I. W. N. (2019). Strategic management in fatwa-making process. Academy of Strategic Management Journal, 18(4), 1-6.

Yasin, M. F. B. M., Embong, A. H., Khairuldin, W. M. K. F. W., Rahim, A., Abdullah, Sulaiman, R., Mutalib, N. A. (2018). Contributions of technology towards development of Qur'anic tajweed knowledge. International Journal of Civil Engineering and Technology, 9(6), 1340-1352.

NACA. (2015). From https://www.avert.org/professionals/hiv-around-world/sub-saharanafrica/nigeria\#footnote6_dz0ywfz

NACA. (2017). From https://www.avert.org/professionals/hiv-around-world/sub-saharanafrica/nigeria\#footnote1_2o3ezks

NACA. (2019). NACA NIGERIA - NACA Nigeria. Retrieved from https://naca.gov.ng/

Namadi, M. M. (2019). Awareness, Knowledge And Attitudes Towards HIV_AIDS Among Long Distance Truck Drivers In Kano State, Nigeria _ 78454. 
INTERNATIONAL JOURNAL OF ACADEMIC RESEARCH IN BUSINESS AND SOCIAL SCIENCES

Vol. 10, No. 4, April, 2020, E-ISSN: 2222-6990 @ 2020 HRMARS

Odimegwu, C. O., Akinyemi, J. O., \& Alabi, O. O. (2017). HIV-Stigma in Nigeria: Review of Research Studies, Policies, and Programmes. AIDS Research and Treatment, Vol. 2017, pp. 1-13. https://doi.org/10.1155/2017/5812650

Khairuldin, W. M. K. F. W., Anas, W. N. W. I. N., Embong, A. H., Hassan, S. A., Hanapi, M. S., \& Ismail, D. (2019). Ethics of mufti in the declaration of fatwa according to islam. Journal of Legal, Ethical and Regulatory Issues, 22(5), 1-6.

Rueda, S., Mitra, S., Chen, S., Gogolishvili, D., Globerman, J., Chambers, L., ... Rourke, S. B. (2016). Examining the associations between HIV-related stigma and health outcomes in people living with HIV/AIDS: a series of meta-analyses. BMJ Open, 6(7), e011453. https://doi.org/10.1136/bmjopen-2016-011453 HIV/AIDS, Geneva, Switzerland

UNAIDS. (2017). https://www.avert.org/professionals/hiv-around-world/sub-saharanafrica/nigeria\#footnote4_x4fkeo4

UNAIDS 'AIDSinfo'. (2018) from https://www.avert.org/professionals/hiv-around-world/subsaharan-africa/nigeria\#footnote5_ewcqz1h 